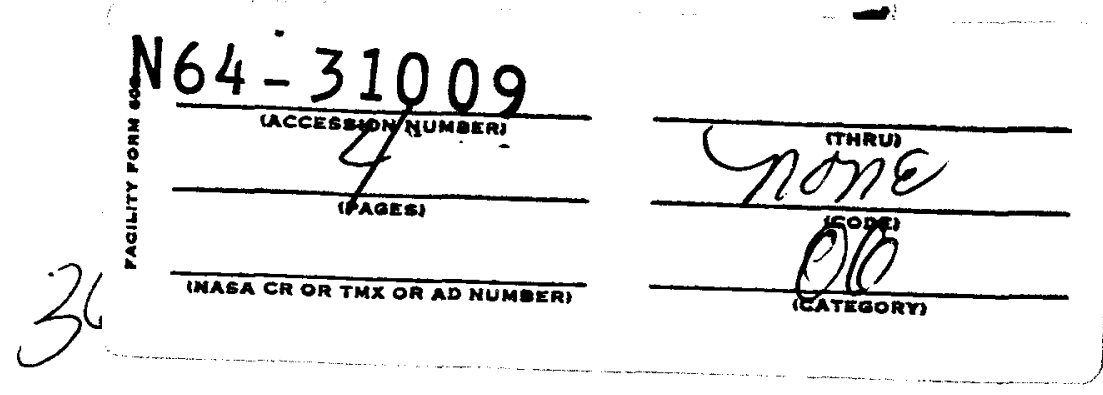

\title{
Results of Studies on a Twin-Gyro Attitude-Control System for Space Vehicles
}

\author{
Armando E. Lopez, * JaCk W. Ratcliff, $\dagger$ and Jerry R. Havilu \\ NASA Ames Research Center, Moffett Field, Calif.
} \begin{abstract}
of arc.
\section{Nomenclature}

The system studied here consists of a twin-gyro controller for each of three orthogonal axes of a space vehicle. With a twin-gyro controller about each axis, the cross coupling generally associated with systems using a single gyro about each axis is eliminated. The elimination of this cross coupling allows the use of large gimbal angles, so that a large portion of the momentum stored in the gyros is available for transfer to vehicle. The control system had rapid response and good damping characteristics. In an automatic closed-loop mode the control system was able to maintain the attitude of the simulator to within 1 sec of arc about all axes. In a manually operated mode the pilot was able to maintain attitude to within 5 sec

$\begin{array}{ll}H & =\begin{array}{c}\text { total angular momentum about momentum- } \\ \text { exchange axis }\end{array} \\ h & =\text { angular momentum of one gyro } \\ K_{1}, K_{2}, K_{3}= & \text { gain constants } \\ \theta_{c} & \begin{array}{c}\text { angular position of gyros with respect to spin- } \\ \text { reference axis }\end{array} \\ \varphi, \theta, \psi \quad & \begin{array}{c}\text { attitude angles about roll, pitch, and yaw axes of } \\ \text { vehicle }\end{array} \\ \tau & =\text { time constant }\end{array}$

\section{Introduction}

D URING the midcourse phase of manned space flights, while navigational sightings are being made, the attitude of the vehicle will have to be stabilized to some extent. The attitude limits and rate requirements of the stabilization system will depend on the navigational sighting equipment and the accuracy required. It may be desirable to stabilize the attitude of the vehicle to within a few seconds of are to insure the accuracy needed for mission accomplishment.

One attractive approach to vehicle attitude control is the use of twin-gyro controllers as torque sources. With a twingyro controller for each axis, the gyroscopic cross coupling inherent in a single-gyro system is eliminated, thereby allowing large gimbal angle deflections, so that a major portion of the momentum stored in the gyros is available for transfer to the vehicle. The elimination of cross coupling also permits the use of an independent control system for each

Presented as Preprint 63-332 at the AIAA Guidance and Control Conference, Cambridge, Mass., August 12-14, 1963; revision received $\mathrm{March} 30,1964$.

* Research Scientist. Member AIAA.

† Research Scientist.

$\mp$ Research Scientist (deceased). axis. This facilitates the introduction of a pilot into the control loop.

An investigation has been completed at NASA Ames Research Center on the attitude stabilization of a large space vehicle that uses twin gyros as torque sources. Two control systems-automatic closed-loop and pilot-operatedhave been investigated. The automatic system was capable of maintaining attitude stabilization to within 1 sec of arc. The pilot-operated system was capable of attitude stabilization to 5 sec of arc.

\section{Theory of Twin-Gyro Controllers}

The construction of the twin-gyro controllers was based on the study reported in Ref. 1. Synchros were used as gimbal position sensors, and geared servomotors were used to position the gimbals.

A twin-gyro controller is shown schematically in Fig. 1. The two gyros are shown supported by a framework rigidly attached to a vehicle. With no input signal, the gyros have their angular momentum vectors aligned along the spin reference axis but in opposite directions. For a given input signal, the gyros are forced to turn through equal and opposite angles $\pm \theta_{c}$. The components of momentum along the momentum-exchange axis add directly. The components of momentum along the other two axes cancel. The component of momentum about the momentum-exchange axis is $H=2 h \sin \theta_{c}$, where $H$ is the total momentum about the momentum exchange axis and $h$ is the angular momentum of each gyro. The torque applied to the vehicle, through the framework, is the time-rate change of momentum $2 h \dot{\theta}_{c} \cos \theta_{c}$.

Each twin-gyro controller had an angular momentum of about $110 \times 10^{6} \mathrm{~g}-\mathrm{cm}^{2} / \mathrm{sec}$ or about $8 \mathrm{slug}-\mathrm{ft}^{2} / \mathrm{sec}$. The servomotors were capable of a maximum gimbal angle rate of change $\dot{\theta}_{c}$ of about $1 \mathrm{rad} / \mathrm{sec}$. The resulting torque to the 


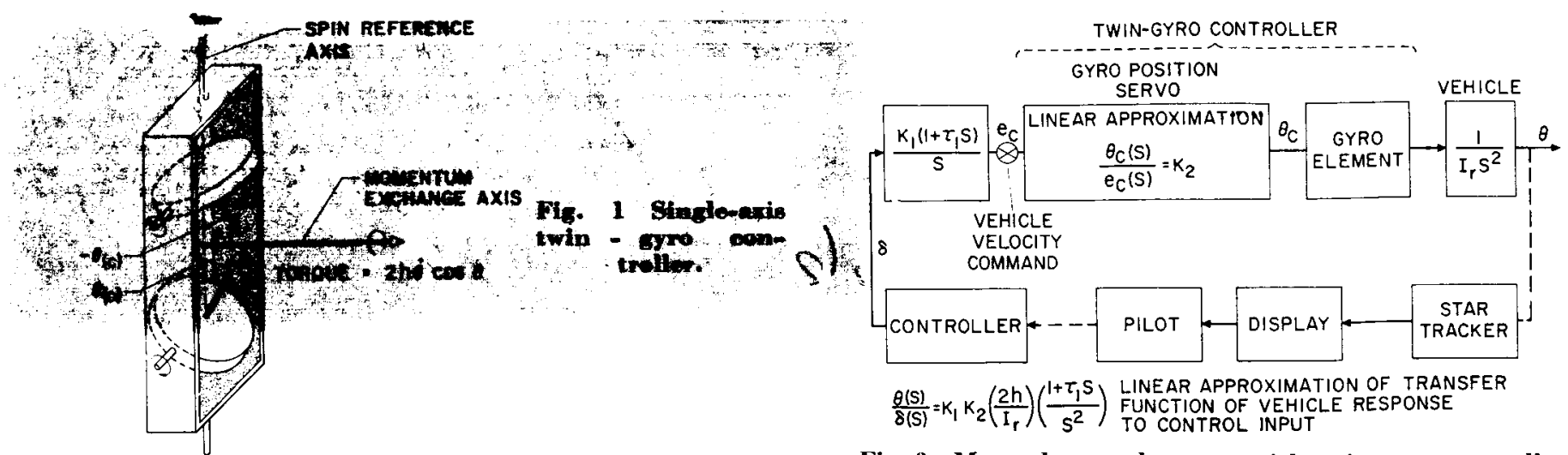

vehicle was therefore limited to about $8 \mathrm{ft}-\mathrm{lb}$. The total weight of each of the twin-gyro controllers, including gyro elements, synchros, servomotors, framework, and associated electronics was about $21 \mathrm{lb}$.

\section{Test Apparatus}

The basic elements of a single-axis automatic twin-gyro control system are shown in Fig. 2. This system consisted of an attitude sensor, signal processing circuit, a twingyro controller, and a vehicle. Three single-axis control systems were mounted on a space vehicle attitude-motion simulator, with the momentum-exchange axes of the gyros mounted orthogonally for control about the three-body axes of the simulator.

External applied torques in the form of small jet-reaction torques were supplied to return the gyros automatically to their neutral position, $\theta_{c}=0$, whenever the gimbal angle exceeded $60^{\circ}$. With the exception of gains and inertia values, the control systems about all three axes were identical.

Certain modifications to the automatic control system were made in order to include a pilot in the control loop (see Fig. 3) - the introduction of a pilot controller and attitude display and the elimination of the lead-lag networks. Preliminary runs with a pilot-operated system were conducted with and without the lead-lag network. The pilots' opinion was that the system characteristics were more desirable without this network.

\section{Vehicle Simulation}

A sketch of the vehicle simulator with which these tests were conducted is presented in Fig. 4. This simulator is supported at the center by a ball and socket, with low-friction air bearing. Measurements on the gas-bearing support indi-

\begin{tabular}{|c|c|c|c|c|c|c|c|c|c|c|c|}
\hline \multirow{2}{*}{\multicolumn{4}{|c|}{$\begin{array}{l}\text { SIGNAL PROCESS } \\
\text { NTEGRAL PLUS } \\
\text { PROPORTIONAL }\end{array}$}} & \multicolumn{5}{|c|}{ TWIN-GYRO CONTROLLER } & \multirow{2}{*}{\multicolumn{2}{|c|}{$\begin{array}{l}\text { EXTERNAL } \\
\text { APPLIED } \\
\text { TORQUE }\end{array}$}} & \multirow[b]{2}{*}{$\begin{array}{l}\text { VEHICLE } \\
\text { ANGLEE }\end{array}$} \\
\hline & & & & \multicolumn{2}{|c|}{ GYRO } & ITION 5 & SERV & & & & \\
\hline$k_{1}(1+$ & $\left.\tau_{1} \mathrm{~s}\right)$ & \multicolumn{2}{|c|}{$\left(1+\tau_{2} s\right)$} & \multicolumn{5}{|c|}{$\mathrm{K}_{2}$} & \multirow{2}{*}{$\begin{array}{l}2 \mathrm{hs} \\
\cos \theta\end{array}$} & & \\
\hline \multicolumn{2}{|c|}{$\mathbf{s}$} & \multicolumn{2}{|c|}{$\left(1+\tau_{3} s\right)$} & $\left.i_{4} s\right)$ & $1+\tau_{5}$ & s) $\left(1+i_{6}\right.$ & s)iit & $\left.\tau^{2}{ }^{5}\right)$ & & $I_{r} s^{2}$ & \\
\hline \multicolumn{2}{|c|}{$\begin{array}{l}\text { VEHICLE } \\
\text { ATTITUDE } \\
\text { COMMAND }\end{array}$} & \multicolumn{2}{|c|}{$\begin{array}{l}\text { LEAD-LAG } \\
\text { NETWORK }\end{array}$} & $\mathrm{HIO}$ & $\begin{array}{l}\mathrm{LE} \\
\mathrm{OMMN}\end{array}$ & $\begin{array}{l}\text { ELOCIT } \\
\text { AND }\end{array}$ & & \multicolumn{2}{|c|}{$\begin{array}{c}\text { GYRO } \\
\text { ELEMENTS }\end{array}$} & VEHICLE & \\
\hline & & & & & & & & \multicolumn{2}{|c|}{$\begin{array}{c}\text { ATTITUDE } \\
\text { SENSOR }\end{array}$} & $\overline{\left(1+\tau_{8} s\right)}$ & \\
\hline & $K_{1}$ & $\mathrm{~K}_{2}$ & $\mathrm{k}_{3}$ & $\pi$ & $\tau_{2}$ & $\tau_{3}$ & $\tau_{4}$ & $\tau_{5}$ & $\tau_{6}$ & $\tau_{7}$ & $\tau_{8}$ \\
\hline ROLL & 0.3 & 0.17 & $1.5 \times 10^{4}$ & 1 & 0.2 & 0.015 & 0.2 & 0.04 & $\begin{array}{l}10^{-4+} \\
j .03\end{array}$ & $\begin{array}{l}10^{-4-}- \\
\text { j.03 }\end{array}$ & 0.1 \\
\hline PITCH & 3 & 0.17 & $1.5 \times 10^{4}$ & 1 & 0.2 & 0.015 & 0.2 & 0.04 & $\begin{array}{l}10^{-4}+ \\
j .03\end{array}$ & $\begin{array}{l}10^{-4}- \\
j .03\end{array}$ & 0.1 \\
\hline YAW & 3 & 0.17 & $1.5 \times 10^{4}$ & 1 & 0.2 & 0.015 & 0.2 & 0.04 & $\underset{1.03}{10^{-4}+}$ & $\begin{array}{l}10^{-4}- \\
j .03\end{array}$ & 0.1 \\
\hline
\end{tabular}

Fig. 2 Single-axis automatic twin-gyro control system.
Fig. 3 Manual control system with twin-gyro controller.

cate that the combined friction and self-induced torques of the gas-bearing support are in the order of a few hundred dynes-cm (or about $10^{-5} \mathrm{ft}-\mathrm{lb}$ ).

Prior to each data run, the vehicle was balanced so that its center of gravity coincided with its center of rotation as accurately as could be determined. This was done to eliminate both static stability of the vehicle and constant gravity torques.

Although the vehicle simulator was originally designed to enable a pilot to control the attitude from on board the vehicle, all the data presented in this paper for a manually operated system were obtained with the pilot operating the control system from a fixed cockpit situated near the simulator.

\section{Attitude Sensor}

The attitude sensor for this investigation was a set of two star trackers mounted off the vehicle with two light sources on the vehicle. One sensor was mounted to the side of the vehicle for detecting roll attitude, and the other sensor was mounted in front of the vehicle to detect yaw and pitch attitudes. These sensors had a sensitivity of $100 \mathrm{mv} /$ are sec and a linear output between \pm 30 sec of arc. These sensors were calibrated with the use of an autocollimator, and the results indicated a threshold level well below $\frac{1}{4}$ arc sec.

\section{Attitude Display}

The attitude of the simulator was displayed to the pilot as a horizon line on an oscilloscope (Fig. 5). An attitude error of 5 sec of are about the pitch axis displaced the horizon line vertically $1 \mathrm{~cm}$; an error of $5 \mathrm{sec}$ of arc about the yaw axis displaced the heading marker $1 \mathrm{~cm}$, and a roll error of 5 sec of arc rotated the line approximately $14^{\circ}$.

This display differed from a conventional artificial horizon in that the displacement of the horizon, because of a pitchattitude error, was in a vertical direction rather than normal to the horizon. This scheme was justified on the basis of the
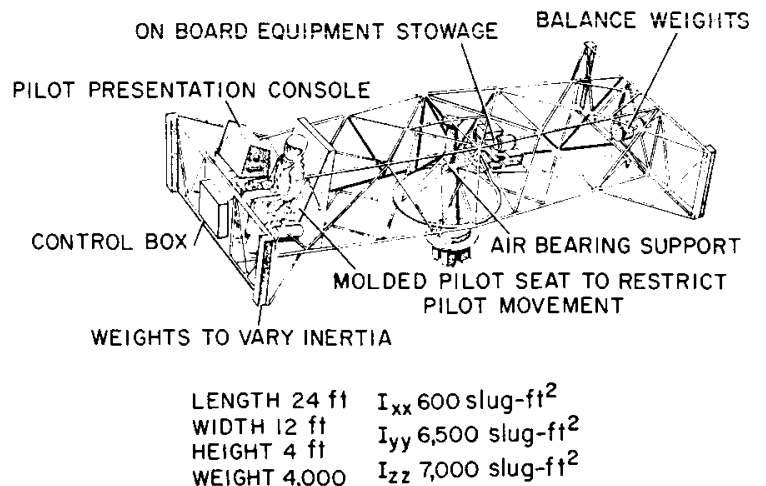

Fig. 4 Space vehicle simula tor. 


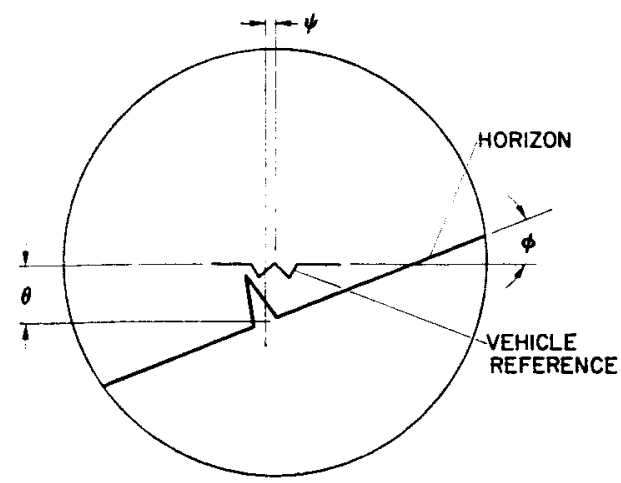

Fig. 5 Vehicle attitude display.

small-angle deflections in this investigation. The pilots commented that this system was appropriate for the control task involved.

\section{Pilot Controller}

The proportional pilot controller consisted of a two-axis pencil-type controller for roll and pitch control and a set of toe pedals for yaw control. The characteristics of this controller system are shown in Fig. 6.

\section{Signal Processing}

The signal processing was accomplished on an analog computer. The flexibility of the computer was useful in determining the time constants and gains in the system in order to obtain the desired response and damping characteristics. It might be expected that the transfer functions of the signal processing unit could be developed for the actual vehicle with miniature components having fixed characteristics. The frequency response of the simulator about the yaw axis, while being controlled by the automatic closed-loop system, is shown in Fig. 7. It can be seen that this system had a breakpoint at about $1 \mathrm{cps}$. The response characteristics about the pitch and roll axes were similar to the response about the yaw axis.

\section{Results}

\section{Automatic Control System}

The task for the automatic control system was to control the vehicle at as precise an attitude as practical and still to maintain reasonable dynamic response and damping characteristics.

The performance of the automatic control system is demonstrated by the time history presented in Fig. 8 , in which the ability of the automatic system to stabilize the attitude of the vehicle is demonstrated. Although no deliberate disturbances were introduced, the simulator was subject to

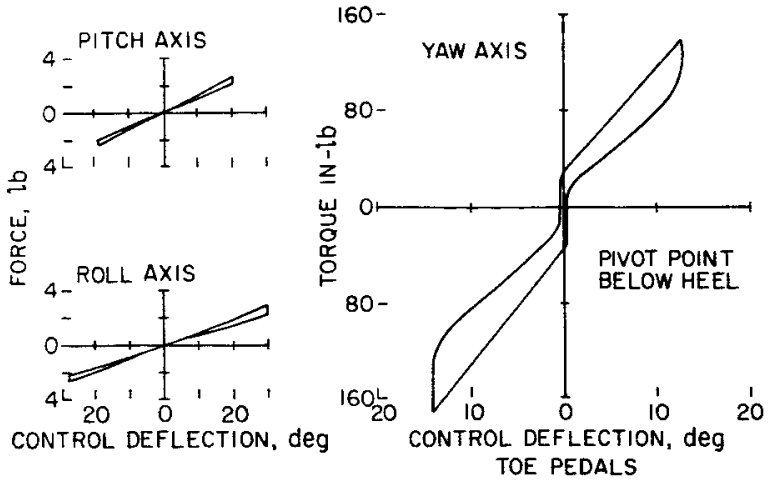

Fig. 6 Control force characteristics.

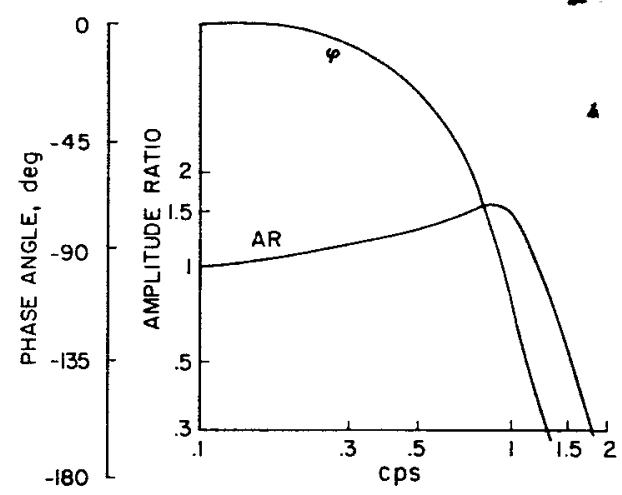

Fig. 7 Yaw-axis frequency response.

random disturbances from circulation of air about the simulator. In the presence of these random disturbances, the attitude of the vehicle was held to within $1 \mathrm{sec}$ of arc. The response to a step command in vehicle attitude was rapid and, following the first overshoot, showed reasonable damping characteristies. Within a few seconds of time, the vehicle was stabilized to within 1 sec of arc of the commanded attitude.

The dynamic behavior shown in Fig. 8 is typical for the control characteristics about all axes. This is shown in the time histories given on the left side of Fig. 9 , where it is seen
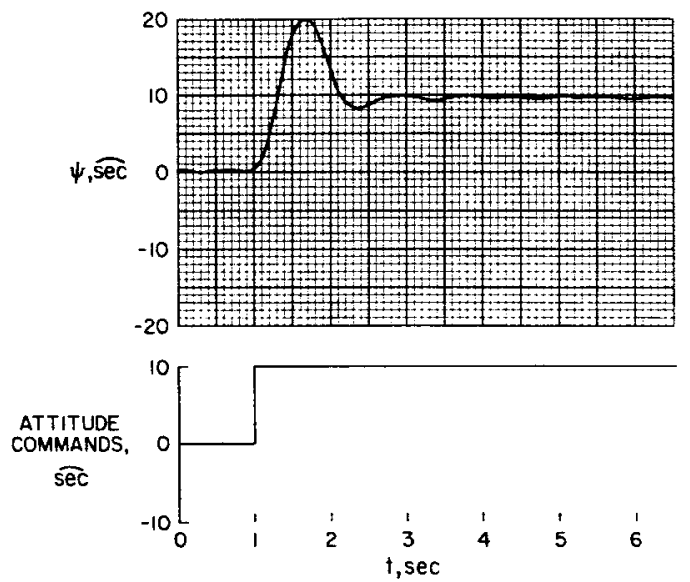

Fig. 8 Response to step attitude command about the yaw axis.

that step commands in attitude were introduced about all three axes simultaneously.

Step commands of vehicle velocity were introduced which simulated disturbances caused by movements of the occupants

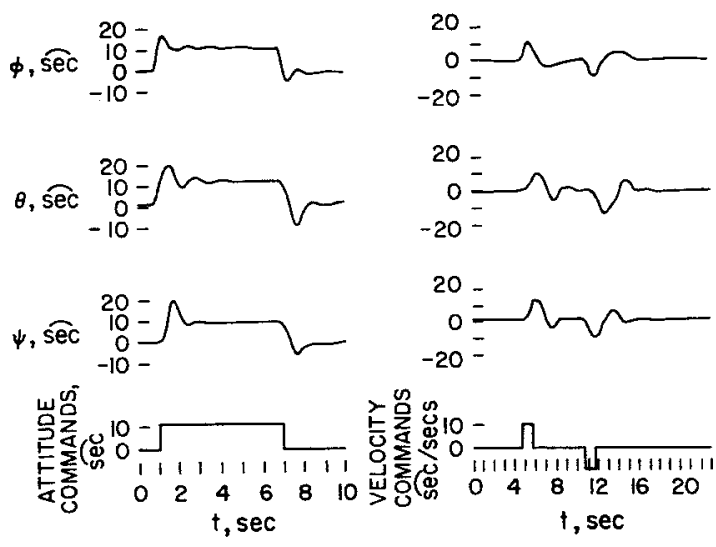

Fig. Automatic twin-gyro control system. 


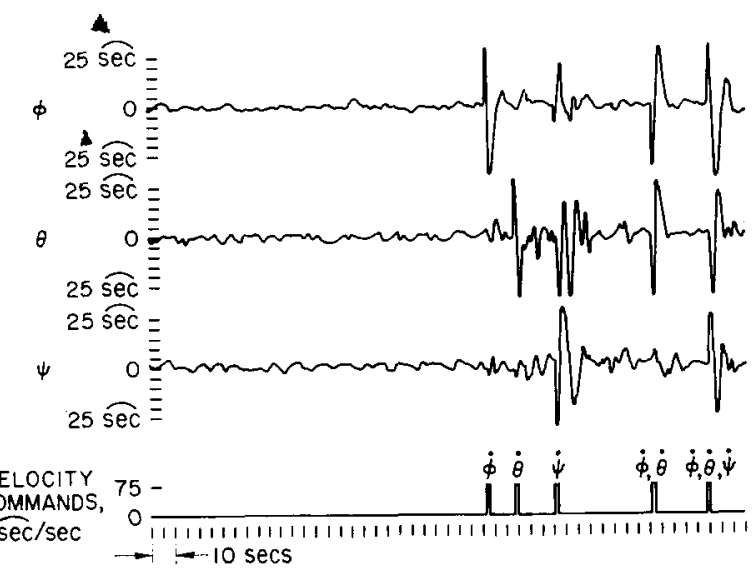

Fig. 10 Manually controlled twin-gyro system.

of the vehicle. The time history of attitude shown on the right side of Fig. 9 shows the dynamic response of the simulator while subjected to step commands of vehicle velocity of $10 \mathrm{sec}$ of arc/sec for $1 \mathrm{sec}$ of time. Step commands up to $100 \mathrm{sec}$ of arc/sec for $1 \mathrm{sec}$ of time were introduced without exceeding the ability of the twin-gyro system to stabilize the vehicle. Disturbances up to $100 \mathrm{sec}$ of arc/sec represent a typical movement of an occupant of a vehicle the size of the Apollo. In a vehicle with about 14,000 slug- $\mathrm{ft}^{2}$ inertia about the pitch axis, an occupant seated at the mass center would command an attitude change of $20 \mathrm{sec}$ of arc while moving his hands from an armchair position to a position over his head.

\section{Manual Control System}

The pilot's task during these tests was to maintain the attitude of the vehicle to within \pm 5 sec of arc about all three axes. After completion of a 2-min period of undisturbed flight, deliberate disturbances were introduced, and the pilot's task was to return the vehicle to within \pm 5 sec of are about all axes as quickly as possiblc.

The manual control system was tested under the same conditions as the automatic system, with step commands in vehicle velocity simulating disturbances caused by occupant movement. Figure 10 is a time history of vehicle attitude during a typical run with a manually operated control system. Although no deliberate disturbances were introduced for the first $2 \mathrm{~min}$, the system was subject to minor disturbances because of air circulating about the simulator and random inputs by the pilot. It can be seen in this figure that the pilot could maintain attitude to within 5 sec of arc during the undisturbed portion of the flight. When the disturbances were introduced about one or two axes simultaneously, the pilot was capable of returning the vehicle to the prescribed limits rapidly.

The majority of the data were obtained with a reserve military pilot who had about $850 \mathrm{hr}$ jet-flight experience. The remaining data were obtained with an engineering test pilot who had about $2400 \mathrm{hr}$ jet-flight experience. The pilots rated the system as acceptable but having certain undesirable characteristics, namely, the lack of vehicle static and dynamic stability. They stated that although the control task was not exceptionally difficult to perform, it did require their undivided attention.

\section{Conclusions}

In conclusion, it has been demonstrated that an automatic twin-gyro system can stabilize a large space vehicle to within 1 sec of arc. In the manually operated mode, the pilot was able to stabilize the vehicle to within $\pm 5 \mathrm{sec}$ of are.

\section{Reference}

1 Amster, M. N., Anderson, R. P., and Williams, H. M., "Analysis of twin-gyro attitude controller; final summary report," Chance Vought Aircraft, Inc. EL-EOR-13005 (June $16,1960)$. 